\title{
Theorising the Microfoundations of analytics empowerment capability for humanitarian service systems
}

\author{
Shahriar Akter ${ }^{1}$ (D) Saradhi Motamarri ${ }^{1}$ (D) - Shahriar Sajib ${ }^{2} \cdot$ Ruwan J. Bandara $^{1}$. \\ Shlomo Tarba ${ }^{3}$. Demetris Vrontis ${ }^{4}$
}

Accepted: 27 October 2021

(c) The Author(s), under exclusive licence to Springer Science+Business Media, LLC, part of Springer Nature 2021

\begin{abstract}
The world is facing an unprecedented humanitarian crisis due to the COVID-19 pandemic. Humanitarian service systems are being empowered to tackle this crisis through the use of vast amounts of structured and unstructured data to protect vulnerable individuals and communities. Analytics has emerged as a powerful platform to visualise, predict, and prescribe solutions to humanitarian crises, such as disease containment, healthcare capacity, and emergency food supply. However, there is a paucity of research on the microfoundations of the humanitarian analytics empowerment capability. As such, drawing on dynamic capability theory and by means of a systematic literature review and thematic analysis, this study proposes an analytics empowerment capability framework for humanitarian service systems. The findings show that analytics culture, technological sophistication, data-driven insights, decision making autonomy, knowledge and skills, and training and development are crucial components of the analytics empowerment's capability to sense, seize, and remedy crisis situations. The paper discusses both theoretical and practical research implications.
\end{abstract}

\footnotetext{
Shahriar Akter

sakter@uow.edu.au

Saradhi Motamarri

saradhi@uow.edu.au

Shahriar Sajib

shahriar.Sajib@uts.edu.au

Ruwan J. Bandara

hmrjb180@uowmail.edu.au

Shlomo Tarba

s.tarba@bham.ac.uk

Demetris Vrontis

vrontis.d@unic.ac.cy

1 School of Business, University of Wollongong, Wollongong, NSW 2522, Australia

2 UTS Business School, University of Technology Sydney, 15 Broadway, Ultimo, NSW 2007, Australia

3 The Department of Strategy and International Business, University of Birmingham, Edgbaston, Birmingham B15 2TT, UK

4 Department of Marketing, School of Business, University of Nicosia, 1700 Nicosia, Cyprus
} 
Keywords Analytics empowerment capability $\cdot$ Humanitarian analytics $\cdot$ Microfoundations of dynamic capability

\section{Introduction}

The COVID-19 pandemic is having a devastating impact on tens of millions of people, presenting an unprecedented challenge to public health and food security, and causing humanitarian crises across the world (World Health Organization, 2021). The use of big data analytics plays a crucial role in the real-time visualization of humanitarian crisis indicators (e.g., infection trends, case numbers, epidemic distribution, etc.) and in managing humanitarian operations (Akter \& Wamba, 2019; Altay et al., 2018; Dubey \& Gunasekaran, 2016; Dubey et al., 2019; Jia et al., 2020; Sheng et al., 2020). In a humanitarian crisis context, big data refers to various types of structured and unstructured information including open data (e.g., publicly available datasets and web contents), sensor-based data (e.g., mobile traffic and satellite images), crowdsourcing (e.g., SMS and hotlines), and any operational information based on metadata records (Gazi \& Gazis, 2021). Big data-leveraging humanitarian analytics has become a critical component in aiding infection control initiatives, analysing emergency responses, and modelling virus transmission (Garattini et al., 2019). A lack of analytics can paralyze the operations of humanitarian service systems by depriving them of correct or adequate insights, which has been evidenced by the recent COVID outbreak in India, in which there has been a failure to predict infection rates and the demand for hospital beds, medicines, oxygen, essential drugs, and tests (Biswas, 2021). Hence, the challenge for humanitarian service systems is how to empower operations managers with analytics insights suited to tackle crises such as epidemics, natural disasters, or migration emergencies.

The application of big data analytics to the humanitarian and emergency context is emerging rapidly. The analytics empowerment capability supports a wide range of humanitarian functions such as epidemic surveillance and response, migration trends, healthcare and emergency food, shelter and transportation demands, among others (Gazi \& Gazis, 2021). As such, analytics empowerment has been identified as the world's most valuable resource (The Economist, 2017), which could offer between US\$9.5 trillion and US\$15.4 trillion worth of value to organizations by solving various issues (Henke et al. 2020). Analytics empowerment refers to the process of enhancing employee self-efficacy by means of data-driven analytical insights, whereas the humanitarian service system refers to the configuration of people, process, information, and technologies that delivers value (Maglio \& Lim, 2016). Although the analytics empowerment capability helps to analyze the gravity of humanitarian crises and mobilize resources, little research exists on its microfoundations (Sheng et al., 2020).

Humanitarian service organisations need to accommodate serious uncertainty and rapidly adapt to unprecedented circumstances for the effective delivery of critical services. During a fast-moving environment, individual capabilities can be effectively transformed into actionable collective intellect through open organisation and self-organising process (Felin $\&$ Powell, 2016), whereas organisational capabilities are embedded in the actions and interactions of individuals within the context that organisation is exposed (Barney \& Felin, 2013; Foss, 2011). To create the context for interactions, the design of decision-making activities may result in enabling conditions or constraints for efficient information processing, coordination, integration, sharing and development of knowledge and collective and individual action (Felin et al., 2012). Therefore, during the context of a humanitarian crisis, humanitarian service organisations need to obtain, process, store, analyse and convert the data into 
actionable insights through analytics empowerment capability to enhance the firm's ability to renew its knowledge for effective adaptation and superior performance (Sheng et al., 2020; Dong et al., 2016; Ambrosini et al., 2009; Côrte-Real et al., 2017).

For effective adaptation and superior firm performance during unprecedented, volatile, uncertain, complex and ambiguous nature of environmental context, the significance of innovative business processes emphasises the critical importance of dynamic capabilities (Schoemaker et al., 2018). As humanitarian organisations need to perform rapid adaptation and resource reconfiguration under serious uncertainty and complexity, dynamic capability view (Schoemaker et al., 2018; Winter, 2003; Teece et al., 1997; Eisenhardt \& Martin, 2000; Schilke, 2014; Schilke et al., 2018) can be a useful theoretical lens to investigate humanitarian analytics empowerment capability. As dynamic capabilities are difficult to build and deploy (Teece, 2009; Teece et al., 1997), the application of microfoundations perspective will allow managers to gain in-depth knowledge of the underlying elements to build and institute the intended dynamic capability (Teece, 2007). Therefore, an in-depth understanding of the microfoundations of organisational capabilities will allow managers to determine strategic considerations and the priorities for adaptation and superior organisational performance (Teece, 2007). Microfoundations can be contexts specific (Felin \& Powell, 2016); therefore, application of microfoundations perspective to investigate analytics empowerment capability will foster superior knowledge about the firm-level humanitarian service performance heterogeneity and competitive advantage specifically in a less understood context of humanitarian service organisations (Barney \& Felin, 2013; Felin et al., 2012; Kindström et al., 2013). As such, this study aims to answer the following research question:

RQ: What are the microfoundations of the analytics empowerment capability in humanitarian service systems?

Drawing on the microfoundations of dynamic capability (DC) theory, this study answers this research question by conducting a systematic review of the literature in order to deduce the microfoundations of the analytics empowerment capability and provide crucial research directions to practitioners, policymakers, and scholars. From a theoretical standpoint, this study introduces analytics empowerment research by extending the ongoing discourse of big data analytics to humanitarian operations management. In practice, the findings highlight the microfoundations of the analytics empowerment capability by illuminating how they can be operationalized in tackling unforeseen crises, such as COVID-19 and beyond.

The rest of the paper is structured as follows. First, we discuss humanitarian service systems and the role played by analytics in them. Second, we clarify our theoretical underpinnings by taking the DC view and its microfoundational perspectives. Third, we discuss the systematic literature review methods and propose our conceptual framework with propositions. Fourth, we discuss the theoretical, practical, and future guidelines of our research.

\section{Literature review}

\subsection{Humanitarian services}

There is no doubt that the world is being faced with rising numbers of emergency situations - from natural to man-made disasters to disease outbreaks that require humanitarian services-with the destructive effects they have on human lives, property, and social stability 
(Akter \& Wamba, 2019). The role played by humanitarian services in disaster, and emergency situations is significant, considering the fact that, in most cases, the affected parties cannot cope with such occurrences by means of their own resources or abilities alone (Hiltz et al., 2014; Shan et al., 2012). Thereby, disaster situations require a rapid and coordinated emergency response from humanitarian organizations, such as supranational aid agencies and NGOs, and other institutions, such as government agencies. Humanitarian organisations, in particular, play a critical and noble role in saving lives and property under severe conditions while facing numerous complexities and constraints.

Humanitarian supply chain (HSC) processes involve "planning, implementation, and managing goods and information from origin and firms to where these goods are consumed" (Bag et al., 2020, p. 2). These HSC processes are often involved in all stages of an emergency or disaster-including pre-disaster or preparedness, operations, and post-disaster or restoration (Behl \& Dutta, 2019) — and manage a range of stakeholders such as aid agencies, donors, government agencies, military forces, community organisations, and aid recipients (Dubey \& Gunasekaran, 2016). These different phases also involve managing varied issues such as inventory management, technology and information management, network planning, transportation and distribution, demand fulfilment, and performance management, to name a few As discussed by Behl and Dutta (2019), HSCs differ from traditional supply chains as they often, if not always, deal with urgency, environmental uncertainty, location accessibility and coordination difficulties.

Dealing with the complexities and constraints involved in humanitarian operations requires a significant amount of preparedness, planning, coordination, resources, and support from different stakeholders (Chakravarty, 2014; John et al., 2012). Moreover, the literature is increasingly highlighting the transforming effects of technology in preventing, mitigating, and managing emergency situations. In particular, the prominence of data-driven solutions is on the rise. Some examples of this include the use of data-driven emergency response decision support systems to effectively allocate and manage resources (Shan et al., 2012), and of web-based decision support systems to measure the degree of resource utilization in emergency situations (Hadiguna et al., 2014). Big data analytics helps to analyze and predict large amounts of data in order to identify potential risks (Akter \& Wamba, 2019). Social media has been found to be highly useful in improving response coordination (Wamba et al., 2019) and information propagation, while cloud computing-based collaboration can enhance the agility of HSCs (Schniederjans et al., 2016). Moreover, several scholars have highlighted the impact of the global positioning system (GPS) and of information, satellite, and other telecommunications technologies in this field (Delmonteil \& Rancourt, 2017; Kabra \& Ramesh, 2015, 2016; Kabra et al., 2017; Özdamar \& Ertem, 2015; Privett, 2016). The focus of this study is on big data analytics and its effect on humanitarian operations, in particular on how its impacts employees. The use of data analytics in humanitarian and emergency services, in general, is discussed in the following section.

\subsection{Analytics in humanitarian service systems}

At present, service organizations are flooded with data, and the humanitarian service sector is no exception; various data sources and formats-such as mobile data, satellite data, transactions and purchasing records, social media posts, and GPS data-in high volumes and velocity are collected by organisations. Given the wide popularity and usability of big data analytics in the service industry (Akter et al., 2019a, 2019b), humanitarian organisations increasingly leverage data analytics into their operations (Papadopoulos et al., 2017; Wamba 
et al., 2015). Data analytics have become critical for today's service organisations, enabling them to derive actionable insights, make effective decisions, create value, and achieve competitive advantages (Gunasekaran et al., 2017; Popovič et al., 2018; Wamba et al., 2018). Further, analytics-driven insights enable firms to seize opportunities, reconfigure resources, plan effectively, and adapt dynamically under changing environments (Maglio \& Lim, 2016; Mikalef et al., 2019; Motamarri et al., 2020).

The literature presents some interesting cases, advantages, and challenges of data analytics in the humanitarian service context. Wamba et al. (2015) focussed on the adoption of big data analytics by the Australian New South Wales State Emergency Services to effectively and successfully conduct their operations through improved decision making (e.g., real-time resource allocation, coordination, and asset movement). Using the case of the 2015 Nepal earthquake and using data analytics, Papadopoulos et al. (2017) showed that swift trust, information sharing, and public-private partnerships are crucial factors in ensuring resilience in supply chains. Griffith et al. (2019) demonstrated the use of a simple and effective analytic method based on open-source imagery tools to generate value for humanitarian operations. In another study based on the case of the 2018 Kerala floods, Nagendra et al. (2020) revealed how data analytics using real-time weather information and geospatial data can improve collaboration and coordination to improve humanitarian relief efforts. Delen et al. (2011) showcased the use of data mining and geographic information-systems-based (GIS) analytics to enhance decision-making and improve inventory management and overall blood supply chain management. In a similar vein and based on the 'resource dependence theory', Prasad et al. (2018) illustrated how, in terms of different data attributes (e.g., volume, velocity, and variety), big data analytics can be leveraged to achieve superior humanitarian outcomes in terms of deliverables, lead-times, cost, and propagation. These examples demonstrate the significant and substantial impact of data analytics in humanitarian context and how they enhance overall humanitarian operations. Table 1 identifies some selected works in this area. We note, however, that there has hitherto been little focus on how data analytics can empower employees and how that capability can affect humanitarian operations.

\section{Theoretical foundations}

\subsection{The dynamic capability view}

Dynamic capabilities (Eisenhardt \& Martin, 2000; Schoemaker et al., 2018; Teece et al., 1997; Winter, 2003) have become a significant theoretical lens in operations research (Di Stefano et al., 2014; Schilke, 2014; Schilke et al., 2018; Tran et al., 2019). The DC view has been applied to investigate service systems (Nenonen et al., 2018; Lenka et al., 2018) and analytics have been identified as a critical microfoundation of DCs (Cao et al., 2019, Mikalef \& Pateli, 2019; Mikalef et al., 2019). From the perspective of evolutionary routines, DCs are perceived as the mechanism whereby organisational resource bases are built and adapted in order to attain the necessary organisational fit with the external environment (Levinthal \& Marino, 2015; Schilke, 2014).

The unprecedented situation caused by the COVID-19 pandemic has highlighted the role played by DCs of the humanitarian service providers to respond to situations of crisis. During an emergency, crisis, or disruption, DCs such as resilience capability play critical roles in the successful recovery of service operations (Ishida, 2020; Makkonen et al., 2014; Mikalef \& Pateli, 2017; Parker \& Ameen, 2018'; Chowdhury \& Quddus 2017; Martinez et al., 2019). 
Table 1 Selected studies using big data and analytics in humanitarian service operations

\section{Relevant studies}

Bag et al. (2020)

Delen et al. (2011)

Dubey et al. (2018)

Goswami et al. (2018)

Griffith et al. (2019)

Nagendra et al. (2020)

Ofli et al. (2016)

Papadopoulos et al. (2017)

Prasad et al. (2018)

Sharma and Joshi (2019)

Wamba et al. (2015)
Data analytics application/relevance

The authors investigated the barriers to the adoption of big data analytics in HSC management, which include: poor management of data generated from multiple sources, having to deal with multiple formats of data, lack of skills for proper data processing and accurate interpretation, poor quality of information sharing, and poor infrastructure

This study showcases the effective use of GIS analytics in effective inventory management, blood supply chain management, and overall decision-making

The authors explored the capability of big data and predictive analytics to enhance both visibility and coordination in HSCs

The authors reviewed the development of disaster management strategies by mining datasets, focussing on analytical techniques to aid disaster detection, prediction, and evolve a strategy

The study provides a real-world example in the context of patient evacuation, showing how data analytics tools can be used to enhance the effective management of humanitarian operations

The authors showed how satellite big data analytics built over real-time weather information and geospatial data, and deployed over a cloud computing platform can improve humanitarian relief operations through enhanced coordination and collaboration among rescue teams

The study presents a hybrid crowdsourcing and real-time machine learning solution suited to rapidly process large volumes of data captured via unmanned aerial vehicles for time-sensitive disaster responses

The study applies data analytics and shows that swift trust, information sharing, and public-private partnerships are crucial factors in ensuring supply chain resilience

The study discusses how the use of big data analytics in terms of different data attributes (e.g., volume, velocity, and variety) can be leveraged to achieve superior humanitarian outcomes

The authors identified the challenges that can emerge in humanitarian operations through over dependency on big data tools. These challenges include digital divide among the population, imperfections in data collection technologies, ethical and data security issues, higher costs, language and cultural issues, and statistical errors

By means of an emergency service case study, the authors explained how big data analytics can improve emergency operations through improved decision making

Bundy et al. (2017) further noted that, to manage complexity and avoid crisis within the context of a highly volatile environment, service systems need to be highly agile and adaptive. For example, in New York, the slow response by the authority and city officials to the threat of the COVID-19 virus and their failure to recognize the early symptoms of increasing patient admission in the hospitals complicated the situation (Advisory Board, 2020). Furthermore, according to health experts, a lack of decisive actions and the spread of misinformation severely delayed the necessary response to the COVID-19 crisis; approximately 19,000 lives 
could have been saved if action had been taken just one week earlier (Kuchler \& EdgecliffeJohnson, 2020). Therefore, the humanitarian service systems' process of rapid response and adaptation during crisis situations requires the precise identification of the critical DCs of concern. It is important to distinguish the humanitarian analytics empowerment capability (HAEC) as a DC to be appropriately situated within the context of our empirical enquiry.

\subsection{Humanitarian analytics empowerment capability: a dynamic capability}

Following the evolutionary perspective, a capability is considered as a higher-level routine or collection of routines that possesses the capacity to continue activities in a systematic and practised approach in order to generate an intended outcome in an ongoing and repetitive manner (Schilke et al., 2018; Winter, 2003). Operational capabilities are characterised as the routines leveraged by firms to earn a living at the present time, whereas DCs aim at reconfiguring organizational resource bases in order to maximise the fit with the changes in the external environment (Teece et al., 1997; Winter, 2003; Zahra et al., 2006; Teece, 2009; Zahra et al., 2006). The DC view distinguishes DCs as distinctive capabilities that operate on lower- or zero-order operational routines, resources, and capabilities in order to address any rapid changes in the external environment (Teece, 2009; Teece et al., 1997).

Empowerment is the process whereby the decision-making capacity of an organisational member is enabled by enacting a downward movement of authority and relaxing the boundaries of vertical control (Menon, 2001; Singh \& Saatcioglu, 2008). Empowered capability is defined as the ability of an organisational member to influence the nature and the content of the service offering and effectively seize opportunities (Vargo et al., 2008; Ordanini \& Parasuraman, 2011; Randhawa et al., 2018). We conceptualize the HAEC as a distinctive DC that integrates and synchronizes the underlying organizational resources, operational routines, and capabilities to enable an appropriate response during a crisis situation, when the HAEC plays integrating and synchronizing roles in developing, enabling, and enacting higher-order DCs of serious importance, such as agility and adaptability, to effectively delegate humanitarian services; therefore, the HAEC can be distinguished as a distinctive DC (Helfat \& Raubitschek, 2018). Next, we will illustrate the microfoundations of the HAEC.

\subsection{The microfoundations of the analytic empowerment capability}

The microfoundation view of routines and capabilities has attracted scholarly attention to the end of developing a superior explanation of the heterogeneity of organizational performance (Barney \& Felin, 2013; Felin et al., 2012; Teece, 2007). Scholars have identified the microfoundations of DCs as the micro level components that underpin routines and capabilities, such as the procedures, distinctive skills, decision rules, organisational disciplines and structures, design of decision-making activities, knowledge development and sharing, information processing, and the integration and coordination activities that create the context for interactions with the external environment (Eisenhardt et al., 2010; Felin \& Powell, 2016; Felin et al., 2012; Schilke \& Goerzen, 2010; Teece, 2007). Within a complex service system setting, the experience of NYC's health and hospitals emphasized the critical importance of analytics and robust intelligence for sound decision making and to forecast with a higher degree of trust during the COVID-19 pandemic (Chokshi \& Katz, 2020). Micro foundation perspectives (Felin et al., 2012, 2015; Schilke, 2014) will facilitate the obtaining a precise insights about the underlyings of a capability that will allow gaining deeper understanding 
of the process of building an analytic empowerment capability to effectively enable humanitarian service systems to respond to crises.

Table 2 identifies the major studies on the micro-foundations of DCs, indicating the scarcity of research exploring the microfoundations of the HAEC.

Table 2 Microfoundations of dynamic capabilities

\begin{tabular}{|c|c|c|c|}
\hline $\begin{array}{l}\text { Microfoundation } \\
\text { research }\end{array}$ & Study type & Study & Main findings \\
\hline $\begin{array}{l}\text { Sustainable } \\
\text { enterprise } \\
\text { performance }\end{array}$ & Theoretical & $\begin{array}{l}\text { Eisenhardt and } \\
\text { Martin, (2000) }\end{array}$ & $\begin{array}{l}\text { The authors suggested new product } \\
\text { development capacities, quality control } \\
\text { procedures, cross functional research and } \\
\text { development teams, knowledge and } \\
\text { technology transfer, and certain performance } \\
\text { measurement systems as critical } \\
\text { microfoundations of DCs }\end{array}$ \\
\hline $\begin{array}{l}\text { Sustainable } \\
\text { enterprise } \\
\text { performance }\end{array}$ & Theoretical & Teece, (2007) & $\begin{array}{l}\text { The conceptualisation of microfoundations as } \\
\text { the underlying distinctive procedures, } \\
\text { processes, skills, organisational structures, } \\
\text { disciplines, and decision making rules of } \\
\text { organisation-level sensing, seizing, and } \\
\text { reconfiguring capabilities }\end{array}$ \\
\hline $\begin{array}{l}\text { Organisational } \\
\text { adaptive } \\
\text { behaviour }\end{array}$ & Empirical & $\begin{array}{l}\text { Makkonen et al., } \\
\text { (2014) }\end{array}$ & $\begin{array}{l}\text { A triangulation of the empirical findings on } \\
\text { organisational adaptive behaviours adopted } \\
\text { during crisis situations by integrating the } \\
\text { extant literature on the DC view, } \\
\text { organisational change, and innovation }\end{array}$ \\
\hline $\begin{array}{r}\text { Routines and } \\
\text { capabilities }\end{array}$ & Theoretical & $\begin{array}{l}\text { Felin et al., } \\
\text { (2012) }\end{array}$ & $\begin{array}{l}\text { Suggesting that individuals, social processes, } \\
\text { and structures are three distinctive types of } \\
\text { the micro-level components underpinning } \\
\text { organisational routines and capabilities }\end{array}$ \\
\hline $\begin{array}{l}\text { Open service } \\
\text { innovation }\end{array}$ & Empirical & $\begin{array}{l}\text { Randhawa et al., } \\
\text { (2018) }\end{array}$ & $\begin{array}{l}\text { Within the context of digital service platforms, } \\
\text { the identification of higher order DCs, such } \\
\text { as empowerment, technological, marketing, } \\
\text { and co-creation capabilities }\end{array}$ \\
\hline TMT leadership & Empirical & $\begin{array}{l}\text { Friedman et al., } \\
\quad(2016)\end{array}$ & $\begin{array}{l}\text { The finding that the transformational } \\
\text { leadership of CEOs fosters microprocesses } \\
\text { in top management teams' strategic decision } \\
\text { making capacities, which enables } \\
\text { organisational adaptive capacity }\end{array}$ \\
\hline $\begin{array}{l}\text { Rapid decision } \\
\text { making }\end{array}$ & Empirical & $\begin{array}{l}\text { Muninger et al., } \\
\text { (2019) }\end{array}$ & $\begin{array}{l}\text { The authors suggested that team } \\
\text { empowerment, top management support, } \\
\text { agile processes, and cycles of testing and } \\
\text { learning enable knowledge flows across } \\
\text { teams and rapid decision making }\end{array}$ \\
\hline $\begin{array}{l}\text { Organisational } \\
\text { level DCs }\end{array}$ & Empirical & $\begin{array}{l}\text { Mikalef et al., } \\
\text { (2019) }\end{array}$ & $\begin{array}{l}\text { The positive impact of big data analytic } \\
\text { capability (BDAC) on organisational level } \\
\text { DCs through the generation of insights that } \\
\text { eventually assist in the building of } \\
\text { incremental and radical innovation } \\
\text { capabilities }\end{array}$ \\
\hline
\end{tabular}


Table 2 (continued)

\begin{tabular}{|c|c|c|c|}
\hline $\begin{array}{l}\text { Microfoundations in } \\
\text { humanitarian contexts }\end{array}$ & Study type & Study & Main findings \\
\hline $\begin{array}{l}\text { Process-oriented DCs } \\
\text { (PODC) }\end{array}$ & Empirical & Kumar et al.,(2020) & $\begin{array}{l}\text { Evidence of the strong } \\
\text { mediating role played by } \\
\text { process oriented DCs } \\
\text { (PODC) in building insights } \\
\text { suited to foster digital } \\
\text { humanitarian capability } \\
\text { (DHC) in improving disaster } \\
\text { risk reduction (DRR) }\end{array}$ \\
\hline $\begin{array}{l}\text { Adaptation and performance } \\
\text { during crises }\end{array}$ & Empirical & Jacob, (2020) & $\begin{array}{l}\text { The author suggested } \\
\text { adaptive, innovation, and } \\
\text { absorptive capabilities as the } \\
\text { critical components of DCs } \\
\text { that have played serious } \\
\text { roles in effectively tackling } \\
\text { the crisis caused by the } \\
\text { COVID-19 pandemic by } \\
\text { maximising organisational } \\
\text { performance through the } \\
\text { creation of value for } \\
\text { stakeholders }\end{array}$ \\
\hline $\begin{array}{l}\text { Viability of supply chains } \\
\text { during pandemics }\end{array}$ & Theoretical & Ivanov, (2020) & $\begin{array}{l}\text { The authors theorized a viable } \\
\text { supply chain (VSC) } \\
\text { considering the perspectives } \\
\text { of resilience, agility, and } \\
\text { sustainability. The VSC } \\
\text { model aids decision-makers } \\
\text { in the design of supply } \\
\text { chains capable of } \\
\text { responding adaptively to } \\
\text { positive changes through } \\
\text { agility and of managing any } \\
\text { negative disturbances }\end{array}$ \\
\hline $\begin{array}{l}\text { Resilience of supply chain } \\
\text { networks }\end{array}$ & Review & Golan et al., (2020) & $\begin{array}{l}\text { The authors revealed the } \\
\text { critical importance of } \\
\text { adopting advanced analytics } \\
\text { in supply chain practices in } \\
\text { order to make such networks } \\
\text { more capable of tackling } \\
\text { uncertain situations and } \\
\text { crises, as evidenced during } \\
\text { the COVID-19 pandemic }\end{array}$ \\
\hline
\end{tabular}

\section{Methods}

To obtain a robust procedure suited to conducting a systematic literature review, we adopted some established guidelines offered in the literature (Akter \& Wamba, 2019; Durach et al., 2017; Tranfield et al., 2003). We thus first developed the protocols for conducting a systematic search across reputed databases, and we then thoroughly used screening techniques following the extraction mechanism to refine the initial findings. Finally, we carried out the analysis and 
synthesis of the final sample, and reported the themes identified in relation to our research questions.

\subsection{Discovery}

We devised an original research question by following the research process outlined by Akter et al. (2020) and Nguyen et al. (2018) through the careful exploration of various scholarly databases, industry white papers, magazines, and newspaper articles. We settled on the following research question: "What are the antecedents of the analytics empowerment capability in humanitarian service systems?" We then followed the guidelines outlined by Sheng et al. (2020) and Dada (2018) to address the research questions by exploring EBSCOhost Business Source Complete, Emerald insight, ScienceDirect and other important journals focussed on cross-disciplinary subjects. To obtain a breadth of relevant research from different fields, we performed a systemic search from 2010 to 2020 using the following keywords: ("big data analytics" OR "analytics" OR "analytics capability" OR "analytics empowerment capabilities") AND (humanitarian analytics* OR analytics in humanitarian service*) AND ("analytics empowerment in humanitarian service" OR "analytics empowerment in service systems"). Our initial search yielded a total of 1820 papers (See Fig. 1).

\subsection{Screening and inclusion}

During this phase, we excluded a total of 1735 articles from the primary discovery of 1820 studies following relevance, quality, and duplication criteria. Based on the guidelines articulated by Sheng et al. (2020) and Akter et al. (2020), we further excluded 55 papers by checking for relevance and conducting a quality appraisal. Based on the cross-citation check of the selected 30 articles, we added 5 more papers. Finally, we obtained a sample of 35 papers, which we carefully reviewed for the purpose of addressing our research question (See Fig. 1).

\subsection{Synthesis and theme identification}

In this section, we present the findings pertaining to the microfoundations of the HAEC drawn from the 35 articles that were considered for thematic analysis and to build the conceptual framework to explicate the antecedents of the analytics empowerment capability in humanitarian service systems. Following the procedure articulated by Akter and Wamba (2019) and Braun and Clarke (2006), we studied our final sample of 35 articles in a rigorous manner in order to reveal the prospective themes. During this phase, to explicate the relevant themes from the dataset (Tuckett, 2005), we applied a coding method utilizing a vital analysis technique (Miles \& Huberman, 1994). Finally, we derived six themes as the microfoundations of the HAEC: analytics culture, technological sophistication, data-driven insights, decision making autonomy, knowledge and skills, and training and development. In the next section, these six microfoundations of the HAEC are discussed based on our findings. 


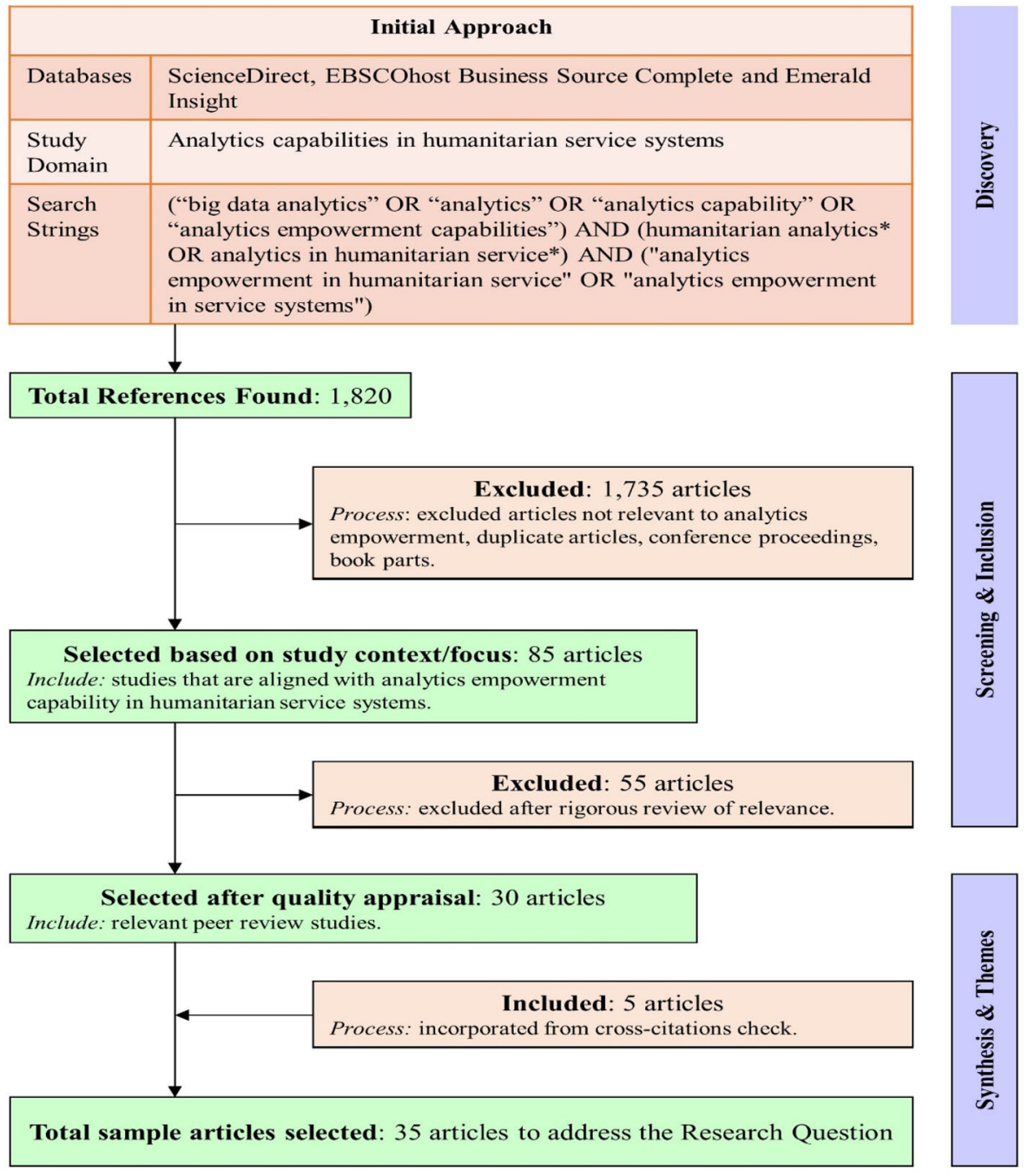

Fig. 1 Protocol for a systematic literature review

\section{Proposed conceptual model of the humanitarian analytics empowerment capability}

By conceptualising the analytics empowerment capability as a DC, we uncovered six microfoundations that are necessary for the development of the HAEC: analytics culture (Ransbotham et al., 2015), technological sophistication (HBR, 2014; Lytle et al., 1998; Teece et al., 1997), data-driven insights (Bowen \& Lawler, 1992; Melhem, 2004), decision making autonomy (Bowen \& Lawler, 1992; Spreitzer, 1995); knowledge and skills (Motamarri et al., 2020), and training and development (Rogg et al., 2001; Teece et al., 1997; Voegtlin et al., 2015). During the ongoing COVID-19 pandemic, the top officials of New York City were unable to decide on a lockdown in a timely manner despite the warnings issued by doctors, 


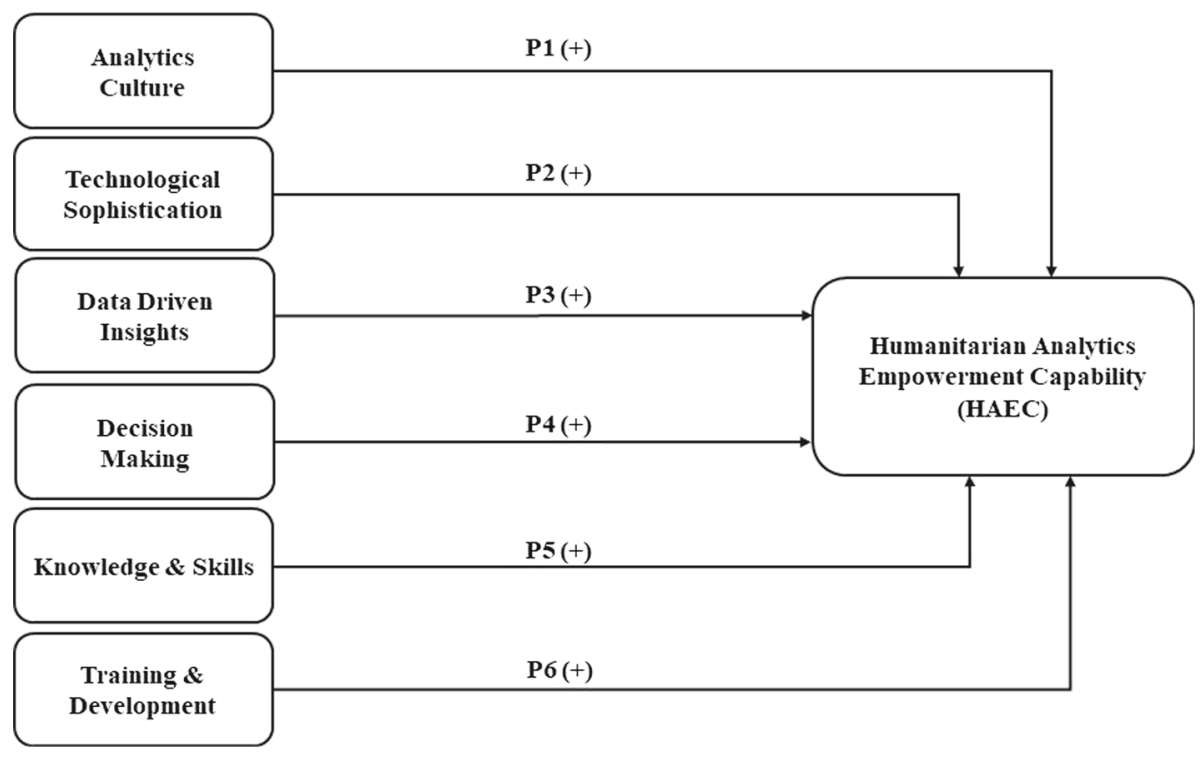

Fig. 2 The proposed framework for the humanitarian analytics empowerment capability

nurses, and schoolteachers (Kuchler \& Edgecliffe-Johnson, 2020; Advisory Board, 2020), which demonstrated a lack of decision-making capability. Further, those top officials told hospitals to increase their capacity by $50 \%$ without providing adequate guidelines regarding the necessary additional staff, beds, and PPE (Advisory Board, 2020). However, along with the shortage of PPEs, the hospitals experienced a shortage of oxygen-related supplies due to the failure to quickly acquire and distribute the extra stock that was available to the supplier (Advisory Board, 2020). Moreover, New York hospitals had to train many newly appointed health workers with no prior experience to tackle the rapid surge of COVID cases (Advisory Board, 2020).

The second COVID-19 wave in India further confirmed that analytics-driven empowerment is a necessary precondition to appropriately anticipate, prepare, and respond to rapid outbreaks (Sky News, 2021). The absence of analytic empowerment of managers, front line employees, and government officials deepened the crisis with of shortage of oxygen supplies, causing a massive loss of lives across India (Sky News, 2021). Therefore, nurturing the microfoundations of the HAEC is necessary to aid in achieving the most effective configuration of people, information, and technologies operating within humanitarian service systems. Scholars have emphasised the investigation of institutions and practices on the agility of service systems (Wilden et al., 2017). The following section discusses each of the microfoundation of the HAEC as a DC suited to avoid catastrophic failures of humanitarian service systems during situations of crisis (Fig. 2).

\subsection{Analytics culture}

The cultural norms of an organisation play a significant bridging role between analytical capabilities and competitive performance leverage. Scholars consider culture to be a "secret sauce" for enacting analytics in execution and derive performance gains (Kiron et al., 2014, 
p. 9). Corritore et al. (2020) also suggested that cultural diversity plays a vital role during the strategy or ideation stage, but may stifle execution. They argued that cultural diversity is not only a function of demography, but also encompasses diversity in beliefs and normative expectations. Kiron et al. (2014) argued that analytics culture can be visualised as made up of four dimensions - namely, behaviours, values, decision-making norms, and outcomes. Elaborating on these lines, Kiron et al. (2014) highlighted that employees should have the discretion to rely on analytics insights even if they deviate from the intuitions of senior management. In the event, if organizational culture does not encourage such empowered decision making based on data, a company's well-meaning investments in technology, harvesting of data, and training of the workforce will fail in the last mile of execution. Thus, organisational culture plays an invisible yet strong role in the success of leveraging analytics capabilities. Following these insights, we propose that:

P1: Organizations that rely on 'analytics culture' will be significantly more likely to enhance the analytics empowerment capability.

\subsection{Technological sophistication}

In an elaborate article on a spectrum of service studies, Ostrom et al. (2015) argued that there is a fundamental shift in how services are delivered and experienced, primarily due to the influence of the information revolution. They deduced 12 key research priorities based on the gap between importance and current knowledge level. Among them, "using big data to advance service" and "leveraging technology to advance service" appeared prominently (Ostrom et al., 2015, p. 127). The respondents recognised the complementary role being played by humans and technology at the interface of service delivery or service encounters (Bowen, 2016; Larivière et al., 2017; Ostrom et al., 2015; Schneider \& Bowen, 2019). Scholars contend that humanitarian service systems should aim at enhancing their services and the creation of value by leveraging analytics (Lavalle, 2009; Wilder et al., 2014). Analytics relies on the extraction of insights from different sets of structured and unstructured data, which may have a manifold influence on the firm. For the success of humanitarian analytics, firms need to invest in a multitude of tools that rest on cognition, prediction, and contextual adaptation and go beyond any qualitative, quantitative, and statistical models (Kiron et al., 2012). Organisations can leverage their technology investments only when these tools and technologies are widely available to their workforce to make effective decisions in (near) real-time. Thus, we propose that:

P2: Organizations that adopt 'technological sophistication' will identify and respond to humanitarian situations more effectively than organizations that rely on traditional technologies.

\subsection{Data-driven insights}

Analytics provide humanitarian service systems with intricate insights into disasters and pandemic outbreaks (Kiron \& Shockley, 2011). Conventionally, these insights are confined to the top of the hierarchy. To generate rapid response in handling humanitarian service systems, senior management need to grant employees access to these analytical insights. Analytically matured humanitarian service systems are preparing their strategies to enable the percolation of critical insights to the customer-facing staff and service touchpoints to better serve their 
customers (Davenport et al., 2010; Overby, 2013). This shows that there is some change in executive thinking in regard to the notion that frontline staff need quality access to information (Brown et al., 2014). Kiron et al. (2012) proposed an integrated framework for big data analytics that encompasses conventional statistical tools and sophisticated applications capable of handling problem cognition, scenario building, and predictive advice. These elements convey the intricate and complex challenges associated with harnessing internal and external data and the generation of actionable advice. An even more complex aspect involves enabling frontline staff to exploit such advice in a manner suited to enhance the service delivered to those seeking assistance from humanitarian service systems. This transcends organisational attributes to become a behavioural issue. Studies have revealed that lower-level employees do not yet fully benefit from this range of new tools and insights (Vesset \& Olofson, 2014). Senior executives recognize this disconnect and are deeply concerned about these issues, which are centred around turning information into action at the frontlines (Brown et al., 2014). Following these insights, we propose that:

P3: The greater the extent to which firms foster 'data-driven insights' to tackle humanitarian situations, the greater the likelihood they will enhance the analytics empowerment capability.

\subsection{Decision-making autonomy}

The success of human service systems hinges on the effective translation of service strategies into operational ones at the point of service delivery, so that employees are able act and make decisions. This implies that organisations have to articulate their service goals and orient their employees at various hierarchical levels (Beaujean et al., 2006). These objectives naturally help in formulating the range of services offered by humanitarian service systems and also in elaborating the extent of their coverage. Employees need to deal with beneficiaries by intricately correlating agency objectives with that of the needy within resource constraints (Kilcourse \& Rosenblum, 2014; McKinsey, 2015; Pires et al., 2006) and deliver assistance (Joseph, 1996). Contrary to common perceptions, decision making is not confined to senior managers alone; employees across the layers and levels of an organization routinely make decisions by assembling the information they obtain from both customers and internal systems. In order to hasten the operational process of integrating decision making as an inherent part of service delivery, employees need to be granted the necessary degree of autonomy, albeit within confined or constrained sets of organisational routines and processes. Thus, we propose that:

P4: The greater the organization's tendency to incorporate 'decision-making autonomy', the greater the likelihood that it will increase the analytics empowerment capability.

\subsection{Knowledge and skills}

Professional contexts and operational environments have drastically changed over the last decade, with contemporary work being highly dependent on information technology (Psoinos et al., 2000), process automation clearly blending with human activities (Bowen, 2016; Larivière et al., 2017), and service delivery relying on both internal and external data sources (Ashrafi et al., 2019). This socio-technical integration requires service personnel to be capable 
of interpreting and valorising data drawn from multiple sources, deducing insights, and acting in real-time. In these evolving contexts, employees must have an in-depth knowledge of their operating environment and the skills needed to make effective decisions (Bowen, 2016; Larivière et al., 2017; Wirtz \& Jerger, 2016). Randolph (1995) interpreted empowerment as "recognising and releasing into the organisation that power that people already have in their wealth of useful knowledge, experience and internal motivation" (p. 20). Bowen and Lawler (1995) argued that empowerment helps employees to unleash their knowledge and skills, which contributes to organizational performance. Following these arguments, the literature establishes that knowledge and skills serve as antecedents to empowerment (Melhem, 2004). The ICT revolution and big data are accelerating consumer awareness; thus, maintaining superior service delivery requires enhancing the knowledge and skills of employees in order for them to possess the knowledge differential needed to make sense of the information conveyed by customers and humanitarian service systems, and to make appropriate decisions in (near) real-time. Thus, we propose that:

P5: Organizations that incorporate 'knowledge \& skills' into their analytics empowerment capabilities will identify and respond to humanitarian situations more effectively than organizations that do not develop these capabilities.

\subsection{Training and development}

As noted earlier, employees entrusted with delivering humanitarian services need to make decisions within the organizational framework and the boundaries of their delegated authority. To cope with the dynamics of changing work situations and organizational processes, employees need to be consistently orientated through training programmes and skill development initiatives (Voegtlin et al., 2015). Organizations may strive to upkeep their technological infrastructure, constantly revise their tools and technological platforms, refresh their procedures and routines and take steps to enhance an analytics culture; however, such efforts will not entail an impact in service delivery until their workforces are adequately trained on continuous improvements and their knowledge and skills are fit to be utilized in actual operational delivery. For these reasons, Total Quality Management (TQM) — a strong precursor to employee participation and empowerment-advocates that training and development activities are not one-off activities; they ought to be continuous (Rafiq \& Ahmed, 1998; Tatikonda \& Tatikonda, 1996; Thamizhmanii \& Hasan, 2010). Thus, we propose:

P6: The greater the extent to which firms foster 'training and development' to analytics empowerment capability, the greater the likelihood they will effectively respond to humanitarian crises.

\section{Discussion}

\subsection{Theoretical implications}

This study advances the microfoundational view of dynamic capability theory (Barney \& Felin, 2013; Felin et al., 2012; Teece, 2007) by explicating microfoundations within the context of humanitarian service systems. Theoretically, our investigation on the HAEC represents a significant transition from contemporary analytic research (Mikalef et al., 2020; 
Dubey et al., 2019a; Gunasekaran et al., 2017; Wamba et al., 2017), which has studied the analytics capability in a broader context, with limited indications in regard to the underlying components of the HAEC. Therefore, the current literature has hitherto offered inadequate insights into how to develop the HAEC due to a lack of appreciation of microfoundations. The findings of our study-which, to the best of the authors' knowledge, is the first of its kind-provide a novel perspective of the process of building the HAEC by considering the specific circumstances of humanitarian service systems. By building a theory of the HAEC from a microfoundational perspective, our study advances the current stream of analytics research in service and operations management (e.g., Fosso Wamba \& Akter, 2019; Kache $\&$ Seuring, 2017).

The unprecedented situation that has emerged due to the COVID-19 pandemic has severely challenged humanitarian service operations. To tackle this challenge, our theoretical development explicates the microfoundations of the HAEC in order to effectively enable humanitarian service operations in a crisis situation. Specifically, our research makes two primary theoretical contributions.

First, it outlines a robust theoretical reasoning and offers rich insights into each microfoundation, explaining its impact on the building of the HAEC. The novelty of our study is represented by its uncovering of the microfoundations of the HAEC. Its findings, which are supported by the existing research on analytics and empowerment (Maglio \& Lim, 2016; Mikalef et al., 2019; Motamarri et al., 2020; Dubey et al., 2021; Fosso Wamba \& Akter, 2019; Queiroz et al., 2020), contribute to the research stream on humanitarian service systems by untangling the microfoundations of the HAEC for effective tackling of pandemic situations.

Second, our findings show that the HAEC plays a necessary enabling role within humanitarian service systems. Our study advances the prior dynamic capability research focussed on uncertain and crisis situations (Ishida, 2020; Parker \& Ameen, 2018; Chowdhury \& Quddus, 2018; Martinez et al., 2019; Wilder et al., 2014) by identifying the HAEC as a DC and providing a detailed illustration of the role it plays within humanitarian service systems. Overall, this study advances the humanitarian service system research stream (Goswami et al., 2018; Griffith et al., 2019; Maglio \& Lim, 2016; Nagendra et al., 2020; Sharma \& Joshi, 2019) by unravelling the mechanism enacted by the HAEC to effectively influence humanitarian operations during a crisis situation.

To summarise, our study makes a theoretical contribution by focussing on the micro foundational view of DC theory and offering a detailed method whereby humanitarian service systems can build their HAEC during a crisis situation. The six microfoundations of the HAEC may guide researchers in investigating their complex interactions and their impact on dynamic organizational capabilities, which are crucial in operational management, especially during humanitarian crises.

\subsection{Practical implications}

The current environmental ambiguities and the time constraints placed by the humanitarian services climate are unprecedented in human history. For these reasons, both scholars and industry practitioners emphasising on providing employees information, tools, and technologies. The humanitarian service systems must respond to these forces and carve a path for sustenance and performance (Nelson, 2003; Ransbotham et al. 2015b). Scholars have been advocating the importance of decentralised and analytics-driven decision making over intuition and of granting access to information where it is needed the most (Bowen \& Lawler, 1992; Day, 1994; Teece, 2007). 
Senior management needs to enable the percolation of the analytics insights to their customer-facing resources in order to provide rapid responses to the needy, and match organisational goals with service level expectations. The current research urges senior managers to focus on data-driven decision making and encourage their staff to break the hierarchical shackles that impede informational flows and stifle decision making at the point of service delivery (Brown et al., 2014).

Humanitarian service organizations can flatten reporting structures and allow their employees to make decisions by removing bureaucratic controls, equip them with the latest technological tools, and adequately train them to work effectively. However, if the service personnel do not leverage these well-intended actions, any empowering initiative will fail to deliver the service objectives and to create value to the needy, thus impacting the organization's repute. Thus, the managers of humanitarian service systems must recognize the psychological hurdles nested in employees and make contingent plans suited to ensure success in empowering initiatives (Argyris, 1998).

Although the core objective of analytics is provide value for the entire organization, it is thus far confined to strategic level, now managers should focus on producing value at the critical juncture of service delivery by focussing on the constituent dimensions of the HAEC (Brown et al., 2014). Senior managers should visualize any operational level difficulties and provide easy to operate tools and technologies to their employees to use effectively (Psoinos et al., 2000). Managers should recognize the integrative role played by all the dimensions of the HAEC (Brown et al., 2014). Last but not least, to fully realize the value of analytics, humanitarian service organizations should provide an adequate budget to train and develop the skills of their employees (Brown et al., 2014; Ransbotham et al. 2015a, 2015b).

\subsection{Limitations and directions for future research}

We conducted this systematic literature review article with the purpose of providing novel and substantively exciting ideas and directions for undertaking research in the area of analytics empowerment capability in the humanitarian service context. However, our review is not without limitations, especially that are inherent to systematic literature review studies. First, there can be issues with generalizability. The review is limited only to the humanitarian service context, and other contexts such as retail or hospitality may reveal different microfoundations of analytics empowerment capability. We suggest that future research probe into different contexts to build a general understanding of the analytics empowerment capability. However, it should also be noted that by having a specific focus on the humanitarian service context, we were able to identify unique microfoundations that are context-specific. Nevertheless, we did not consider analytics empowerment capability in terms of diverse context-specific factors such as firm size or the nature of humanitarian operations. This limitation can be addressed in future empirical research to measure the effects of such firm-level factors.

Despite our efforts to conduct a comprehensive systematic search for relevant articles in diverse databases and careful screening, it is possible that some relevant papers were omitted due to a large number of items in the initial pool. Another limitation that is inherent in review articles emerges from the selection of keywords to answer the research question (Gaur et al., 2021). As we only used a particular set of keywords, there is a possibility that some research items are omitted in the screening process.

We presented HAEC with six dimensions for humanitarian systems. Future research can consider conducting longitudinal or multiple cross-sectional surveys for rigorously investigating our propositions empirically. Empowerment theory identifies empowerment as a 
Table 3 Proposed future research agenda

\begin{tabular}{|c|c|}
\hline Proposed future research agenda & References \\
\hline $\begin{array}{l}\text { Qualitative study of aid agencies to better understand } \\
\text { the operational, analytical paucity, and } \\
\text { empowerment hurdles }\end{array}$ & $\begin{array}{l}\text { Braun and Clarke, 2006), Creswell, (2014), } \\
\text { Johnson, (2001) }\end{array}$ \\
\hline $\begin{array}{l}\text { Scale development studies to validate HAEC } \\
\text { propositions and to assess the impact of HAEC on } \\
\text { organizational outcomes }\end{array}$ & $\begin{array}{l}\text { Hair et al., (2020), Hulland et al., (2018), } \\
\text { Morgado et al., (2017), Motamarri et al., (2020), } \\
\text { Sarstedt et al., (2019) }\end{array}$ \\
\hline $\begin{array}{l}\text { Integration of heterogenous humanitarian datasets and } \\
\text { generation of insights for action encompassing } \\
\text { governance, veracity, privacy, transparency and } \\
\text { granularity }\end{array}$ & Bell et al., (2021) \\
\hline $\begin{array}{l}\text { Assessment of humanitarian supply chains, leveraging } \\
\text { of upstream and downstream capabilities for } \\
\text { innovation and performance enhancement }\end{array}$ & Prasanna, (2021) \\
\hline $\begin{array}{l}\text { Investigation into concceptualisation of humanitarian } \\
\text { service delivery issues, development of } \\
\text { mathematical models to optimize resources and } \\
\text { minimize delivery risks }\end{array}$ & Choi, (2021) \\
\hline $\begin{array}{l}\text { Understanding and overcoming procurement issues in } \\
\text { the delivery of humanitarian aid and the relevance of } \\
\text { analytics and empowerment to frontlines }\end{array}$ & John and Gurumurthy, (2021) \\
\hline $\begin{array}{l}\text { Analysis of humanitarian supply chains (mitigation, } \\
\text { preparedness, response, and recovery) and role of } \\
\text { digital technologies and analytics in } \\
\text { decision-making }\end{array}$ & Marić et al., (2021) \\
\hline
\end{tabular}

"dynamic, highly individualistic, [and] contextually layered process" (Foster-Fishman et al., 1998, p. 507). Therefore, longitudinal studies will be useful to understand the dynamic nature of HAEC. Similarly, multiple cross-sectional surveys can aid in understanding the individual and contextual subtleties.

The study extends the microfoundational discourse of DC theory to the complex, human sensitive realm of humanitarian service systems. On the practical end, the study highlights the need to enhance autonomy and decision-making capabilities at the juncture of delivering human-aid so as it enhances agencies performance in tune with the objectives of United Nations Sustainable Development Goals (UNSDGs). Finally, we synthesize the extant literature and our deductive findings and propose an agenda for future research (Table 3) to advance this debate and make a significant impact on the humanitarian service systems in the years to come.

\section{Conclusions}

Humanitarian service systems need to deliver aid in time-critical, context sensitive, difficult to access, and sometimes overcoming cultural and language barriers. No amount of preparedness at times comes to rescue delivery of aid as the pandameic situations like COVID-19 always challenge human faculties to sieve through massive amounts of information, sense the 
situations and orient the delivery in a very empathetic manner balancing the emotional offsprings of the distressed and needy. Dynamic capabilities enable organisations to cope with dealing such novel threats in a systematic manner and achieve the humanitarian outcomes. However, oft neglected fact is the autonomy bestowed on the frontlines to access analytical insights and make timely and effective decisions. Thus, humanitarian empowerment capability is a determining factor that enables the actors in the contexts of emergency and speed. We did a systematic review of the literature, performed thematic analysis of 35 distilled articles, and deduced the six compoment dimensions of HAEC as: analytics culture, technological sophistication, data-driven insights, decision making, knowledge \& skills, and training \& development. We developed corresponding propositions on the influence of each of these dimensions on HAEC. Then, we discussed on the theoretical and practical implications of the findings.

\section{References}

Advisory Board. (2020). 3 lessons the US can learn from New York's Covid-19 response, Accessed on 9th February 2021. https://www.advisory.com/daily-briefing/2020/06/16/new-york-covid

Akter, S., Bandara, R., Hani, U., Wamba, S. F., Foropon, C., \& Papadopoulos, T. (2019a). Analytics-based decision-making for service systems: A qualitative study and agenda for future research. International Journal of Information Management, 48, 85-95.

Akter, S., Wamba, S. F., \& D'Ambra, J. (2019b). Enabling a transformative service system by modeling quality dynamics. International Journal of Production Economics, 207, 210-226.

Akter, S., Gunasekaran, A., Wamba, S. F., Babu, M. M., \& Hani, U. (2020). Reshaping competitive advantages with analytics capabilities in service systems. Technological Forecasting and Social Change. https://doi. org/10.1016/j.techfore.2020.120180

Akter, S., \& Wamba, S. F. (2019). Big data and disaster management: A systematic review and agenda for future research. Annals of Operations Research, 283, 939-959.

Ambrosini, V., Bowman, C., \& Collier, N. (2009). Dynamic capabilities: An exploration of how firms renew their resource base. British Journal of Management, 20, 9-24. https://doi.org/10.1111/j.1467-8551.2008. 00610.x

Ashrafi, A., Ravasan, A. Z., Trkman, P., \& Afshari, S. (2019). The role of business analytics capabilities in bolstering firms' agility and performance. International Journal of Information Management, 47, 1-15.

Bag, S., Gupta, S., \& Wood, L. (2020). Big data analytics in sustainable humanitarian supply chain: Barriers and their interactions. Annals of Operations Research. https://doi.org/10.1007/s10479-020-03790-7

Barney, J. A. Y., \& Felin, T. (2013). What are microfoundations? Academy of Management Perspectives, 27(2), $138-155$.

Beaujean, M., Davidson, J., \& Madge, S. (2006). The 'moment of truth' in customer service. The McKinsey Quarterly, 62-73.

Behl, A., \& Dutta, P. (2019). Humanitarian supply chain management: A thematic literature review and future directions of research. Annals of Operations Research, 283(1), 1001-1044.

Bell, D., Lycett, M., Marshan, A., \& Monaghan, A. (2021). Exploring future challenges for big data in the humanitarian domain. Journal of Business Research, 131, 453-468. https://doi.org/10.1016/j.jbusres. 2020.09.035

Biswas, S. (2021). Covid-19: How India failed to prevent a deadly second wave. https://www.bbc.com/news/ world-asia-india-56771766

Bowen, D. E. (2016). The changing role of employees in service theory and practice: An interdisciplinary view. Human Resource Management Review, 26, 4-13.

Bowen, D. E., \& Lawler, E. E. I. (1992). The empowerment of service workers: What, why, how, and when. Sloan Management Review, 33, 31-39.

Bowen, D. E., \& Lawler, E. E. I. (1995). Empowering service employees. Sloan Management Review, 36, 73-85.

Braun, V., \& Clarke, V. (2006). Using thematic analysis in psychology. Qualitative Research in Psychology, $3,77-101$.

Brown, B., Court, D., \& McGuire, T. (2014). Views from the front lines of the data-analytics revolution. McKinsey Quarterly. McKinsey. 
Bundy, J., Pfarrer, M. D., Short, C. E., \& Coombs, W. T. (2017). Crises and crisis management: Integration, interpretation, and research development. Journal of Management, 43(6), 1661-1692.

Cao, G., Duan, Y., \& El Banna, A. (2019). A dynamic capability view of marketing analytics: Evidence from UK firms. Industrial Marketing Management, 76, 72-83.

Chakravarty, A. K. (2014). Humanitarian relief chain: Rapid response under uncertainty. International Journal of Production Economics, 151, 146-157.

Choi, T. M. (2021). Fighting against COVID-19: What operations research can help and the sense-and-respond framework. Annals of Operations Research. https://doi.org/10.1007/s10479-021-03973-w

Chokshi, A., \& Katz, H. (2020). Emerging Lessons From COVID-19 Response in New York City. The Journal of the American Medical Association, 323(20), 1996-1997. https://doi.org/10.1001/jama.2020.7310

Chowdhury, M. M. H., \& Quaddus, M. (2017). Supply chain resilience: Conceptualization and scale development using dynamic capability theory. International Journal of Production Economics, 188, 185-204.

Corritore, M., Goldberg, A., \& Srivastava, S. B. (2020). The new analytics culture. Harvard Business Review, $98,76-83$.

Côrte-Real, N., Oliveira, T., \& Ruivo, P. (2017). Assessing business value of big data analytics in European firms. Journal of Business Research, 70, 379-390.

Creswell, J. W. (2014). Research design: Qualitative, quantitative and mixed methods approaches. SAGE Publications.

Davenport, T. H., Harris, J., \& Shapiro, J. (2010). Competeing on talent analytics. Harvard Business Review, $88,52-58$.

Day, G. S. (1994). The capabilities of market-driven organizations. Journal of Marketing, 58, 37-52.

Delen, D., \& Demirkan, H. (2013). Data, information and analytics as services. Decision Support Systems, 55(1), 359-363.

Delen, D., Erraguntla, M., Mayer, R. J., \& Wu, C.-N. (2011). Better management of blood supply-chain with GIS-based analytics. Annals of Operations Research, 185(1), 181-193.

Delmonteil, F.-X., \& Rancourt, M. -̇̀. (2017). The role of satellite technologies in relief logistics. Journal of Humanitarian Logistics and Supply Chain Management, 7(1), 57-78.

Di Stefano, G., Peteraf, M., \& Verona, G. (2014). The organizational drivetrain: A road to integration of dynamic capabilities research. Academy of Management Perspectives, 28(4), 307-327.

Dong, X., Yu, Y., \& Zhang, N. (2016). Evolution and coevolution: Dynamic knowledge capability building for catching-up in emerging economies. Management and Organization Review, 12(4), 717-745.

Dubey, R., \& Gunasekaran, A. (2016). The sustainable humanitarian supply chain design: Agility, adaptability and alignment. International Journal of Logistics Research and Applications, 19(1), 62-82.

Dubey, R., Luo, Z., Gunasekaran, A., Akter, S., Hazen, B. T., \& Douglas, M. A. (2018). Big data and predictive analytics in humanitarian supply chains. The International Journal of Logistics Management, 29(2), 485-512.

Eisenhardt, K. M., Furr, N. R., \& Bingham, C. B. (2010). CROSSROADS-Microfoundations of performance: Balancing efficiency and flexibility in dynamic environments. Organization Science, 21(6), 1263-1273.

Eisenhardt, K. M., \& Martin, J. A. (2000). Dynamic capabilities: What are they? Strategic Management Journal, 21(10-11), 1105-1121.

Felin, T., Foss, N. J., Heimeriks, K. H., \& Madsen, T. L. (2012). Microfoundations of routines and capabilities: Individuals, processes, and structure. Journal of Management Studies, 49(8), 1351-1374.

Felin, T., \& Powell, T. C. (2016). Designing organizations for dynamic capabilities. California Management Review, 58(4), 78-96.

Foss, N. J. (2011). Invited editorial: Why micro-foundations for resource-based theory are needed and what they may look like. Journal of Management, 37(5), 14.

Foster-Fishman, P. G., Salem, D. A., Chibnall, S., Legler, R., \& Yapchai, C. (1998). Empirical support for the critical assumptions of empowerment theory. American Journal of Community Psychology, 26(4), 507-536.

Friedman, Y., Carmeli, A., \& Tishler, A. (2016). How CEOs and TMTs build adaptive capacity in small entrepreneurial firms. Journal of Management Studies, 53(6), 996-1018.

Garattini, C., Raffle, J., Aisyah, D. N., Sartain, F., \& Kozlakidis, Z. (2019). Big data analytics, infectious diseases and associated ethical impacts. Philosophy, and Technology, 32(1), 69-85. https://doi.org/10. 1007/s13347-017-0278-y

Gaur, L., Afaq, A., Singh, G., \& Dwivedi, Y. K. (2021). Role of artificial intelligence and robotics to foster the touchless travel during a pandemic: A review and research agenda. International Journal of Contemporary Hospitality Management. https://doi.org/10.1108/IJCHM-11-2020-1246

Gazi, T., \& Gazis, A. (2021). Humanitarian aid in the age of COVID-19: A review of big data crisis analytics and the General Data Protection Regulation. International Review of the Red Cross, 102(913), 75-94. https://doi.org/10.1017/S1816383121000084 
Goswami, S., Chakraborty, S., Ghosh, S., Chakrabarti, A., \& Chakraborty, B. (2018). A review on application of data mining techniques to combat natural disasters. Ain Shams Engineering Journal, 9(3), 365-378.

Griffith, D. A., Boehmke, B., Bradley, R. V., Hazen, B. T., \& Johnson, A. W. (2019). Embedded analytics: Improving decision support for humanitarian logistics operations. Annals of Operations Research, 283(1-2), 47-265.

Gunasekaran, A., Papadopoulos, T., Dubey, R., Wamba, S. F., Childe, S. J., Hazen, B., \& Akter, S. (2017). Big data and predictive analytics for supply chain and organizational performance. Journal of Business Research, 70, 308-317.

Hadiguna, R. A., Kamil, I., Delati, A., \& Reed, R. (2014). Implementing a web-based decision support system for disaster logistics: A case study of an evacuation location assessment for Indonesia. International Journal of Disaster Risk Reduction, 9, 38-47.

Hair, J. F., Howard, M. C., \& Nitzl, C. (2020). Assessing measurement model quality in PLS-SEM using confirmatory composite analysis. Journal of Business Research, 109, 101-110.

Harvard Business Review. (2014). Frontline managers: are they given the leadership tools to succeed? A Report by Harvard Business Review Analytic Services. HBR, Boston, MA, 1-8.

Hiltz, S. R., Van de Walle, B., \& Turoff, M. (2014). The domain of emergency management information. In B. Van de Walle, M. Turoff, \& S. R. Hiltz (Eds.), Information Systems for Emergency Management (pp. 3-20). Routledge.

Hulland, J., Baumgartner, H., \& Smith, K. M. (2018). Marketing survey research best practices: Evidence and recommendations from a review of JAMS articles. Journal of the Academy of Marketing Science, 46(1), 92-108.

Ishida, S. (2020). Perspectives on supply Chain management in a Pandemic and the post-COVID-19 Era. IEEE Engineering Management Review, 48(3), 146-152. https://doi.org/10.1109/EMR.2020.3016350

Ivanov, D. (2020). Viable supply chain model: Integrating agility, resilience and sustainability perspectiveslessons from and thinking beyond the COVID-19 pandemic. Annals of Operations Research. https://doi. org/10.1007/s10479-020-03640-6

Jacob, B. D. F. P. (2020). Public administration's dynamic capabilities in response to Covid-19 pandemic: AMA's case study [Em linha]. Lisboa: Iscte,. Dissertação de mestrado. [Consult. Dia Mês Ano] Disponível em www:<http://hdl.handle.net/10071/21438>

Jia, Q., Guo, Y., Wang, G., \& Stuart, J. B. (2020). Big data analytics in the fight against major public health incidents (Including COVID-19): A conceptual framework. International Journal of Environmental Research and Public Health. https://doi.org/10.3390/ijerph17176161

John, L., \& Gurumurthy, A. (2021). Are quantity flexibility contracts with discounts in the presence of spot market procurement relevant for the humanitarian supply chain? An exploration. Annals of Operations Research. https://doi.org/10.1007/s10479-021-04058-4

John, L., Ramesh, A., \& Sridharan, R. (2012). Humanitarian supply chain management: A critical review. International Journal of Services and Operations Management, 13(4), 498-524.

Johnson, J. M. (2001). In depth interviewing. In J. F. Gubrium \& J. A. Holstein (Eds.), Handbook of Interviewing Research. Sage Publications.

Joseph, W. B. (1996). Internal marketing builds service quality. Journal of Health Care Marketing, 16, 54-59.

Kabra, G., \& Ramesh, A. (2015). Analyzing ICT issues in humanitarian supply chain management: A SAPLAP linkages framework. Global Journal of Flexible Systems Management, 16(2), 157-171.

Kabra, G., \& Ramesh, A. (2016). Information technology, mutual trust, flexibility, agility, adaptability: Understanding their linkages and impact on humanitarian supply chain management performance. Risk, Hazards, and Crisis in Public Policy, 7(2), 79-103.

Kabra, G., Ramesh, A., Akhtar, P., \& Dash, M. K. (2017). Understanding behavioural intention to use information technology: Insights from humanitarian practitioners. Telematics and Informatics, 34(7), 1250-1261.

Kilcourse, B., \& Rosenblum, P. (2014). Retail analytics moves to the frontline (p. 31). Retail Systems Research.

Kindström, D., Kowalkowski, C., \& Sandberg, E. (2013). Enabling service innovation: A dynamic capabilities approach. Journal of Business Research, 66(8), 1063-1073.

Kiron, D., Prentice, P. K., \& Ferguson, R. B. (2014). The analytics mandate: Findings from the 2014 data, and analytics global executive study and research report. MIT Sloan Management Review, Cambridge, MA, p. 1:21.

Kiron, D., Prentice, P. K., \& Ferguson, R. B. (2012). Innovating with analytics. MIT Sloan Management Review, 54, 47-51.

Kiron, D., \& Shockley, R. (2011). Creating business value with analytics. MIT Sloan Management Review, 53, 57-63.

Kuchler, H., \& Edgecliffe-Johnson, A. (2020). How New York's missteps let Covid-19 overwhelm the US, Financial times, accessed on 8th February 2020: How New York's missteps let Covid-19 overwhelm the US I Financial Times (ft.com) 
Kumar A., Vishwakarma N. K., \& Upadhyay P. (2020). Digital Humanitarianism in a Pandemic Outbreak: An Empirical Study of Antecedents and Consequences. In: Sharma S.K., Dwivedi Y.K., Metri B., Rana N.P. (eds) Re-imagining Diffusion and Adoption of Information Technology and Systems: A Continuing Conversation. TDIT 2020. IFIP Advances in Information and Communication Technology, vol 618. Springer, Cham. https://doi.org/10.1007/978-3-030-64861-9_3

Larivière, B., Bowen, D., Andreassen, T. W., Kunz, W., Sirianni, N. J., Voss, C., Wünderlich, N. V., \& De Keyser, A. (2017). Service Encounter 2.0: An investigation into the roles of technology, employees and customers. Journal of Business Research, 79, 238-246.

Lavalle, S., (2009). Business analytics and optimization for the intelligent enterprise. IBM Institute of Business Value, Somers, NY.

Lenka, S., Parida, V., Sjödin, D. R., \& Wincent, J. (2018). Exploring the microfoundations of servitization: How individual actions overcome organizational resistance. Journal of Business Research, 88, 328-336.

Levinthal, D. A., \& Marino, A. (2015). Three facets of organizational adaptation: Selection, variety, and plasticity. Organization Science, 26(3), 743-755.

Lytle, R. S., Hom, P. W., \& Mokwa, M. P. (1998). SERV* OR: A managerial measure of organizational service-orientation. Journal of Retailing, 74, 455-489.

Maglio, P. P., \& Lim, C.-H. (2016). Innovation and big data in smart service systems. Journal of Innovation Management, 4(1), 11-21.

Makkonen, H., Pohjola, M., Olkkonen, R., \& Koponen, A. (2014). Dynamic capabilities and firm performance in a financial crisis. Journal of Business Research, 67(1), 2707-2719.

Marić, J., Galera-Zarco, C., \& Opazo-Basáez, M. (2021). The emergent role of digital technologies in the context of humanitarian supply chains: A systematic literature review. Annals of Operations Research. https://doi.org/10.1007/s10479-021-04079-z

Martinez, M. G., Zouaghi, F., Marco, T. G., \& Robinson, C. (2019). What drives business failure? Exploring the role of internal and external knowledge capabilities during the global financial crisis. Journal of Business Research, 98, 441-449.

McKinsey. (2015). Big Data, Analytics, and the Future of Marketing \& Sales, Marketing \& Sales. McKinsey \& Company, mckinseyonmarketingandsales.com

Melhem, Y. (2004). The antecedents of customer-contact employees' empowerment. Employee Relations, 26, 72-93. https://doi.org/10.1108/01425450410506913

Menon, S. T. (2001). Employee empowerment: An integrative psychological approach. Applied Psychology, 50, 153-180.

Mikalef, P., Boura, M., Lekakos, G., \& Krogstie, J. (2019). Big data analytics capabilities and innovation: The mediating role of dynamic capabilities and moderating effect of the environment. British Journal of Management, 30(2), 272-298.

Mikalef, P., Krogstie, J., Pappas, I. O., \& Pavlou, P. (2020). Exploring the relationship between big data analytics capability and competitive performance: The mediating roles of dynamic and operational capabilities. Information and Management, 57(2), 103169. https://doi.org/10.1016/j.im.2019.05.004

Mikalef, P., \& Pateli, A. (2017). Information technology-enabled dynamic capabilities and their indirect effect on competitive performance: Findings from PLS-SEM and fsQCA. Journal of Business Research, 70, $1-16$.

Miles, M. B., \& Huberman, A. M. (1994). Qualitative data analysis: An expanded sourcebook. Sage.

Morgado, F. F. R., Meireles, J. F. F., Neves, C. M., Amaral, A. C. S., \& Ferreira, M. E. C. (2017). Scale development: ten main limitations and recommendations to improve future research practices. Psicologia: Reflexão e Crítica. 30(1), 3.

Motamarri, S., Akter, S., \& Yanamandram, V. (2020). Frontline employee empowerment: Scale development and validation using Confirmatory Composite Analysis. International Journal of Information Management, 54, 102177.

Muninger, M. I., Hammedi, W., \& Mahr, D. (2019). The value of social media for innovation: A capability perspective. Journal of Business Research, 95, 116-127.

Nagendra, N. P., Narayanamurthy, G., \& Moser, R. (2020). Management of humanitarian relief operations using satellite big data analytics: The case of Kerala floods. Annals of Operations Research. https://doi. org/10.1007/s10479-020-03593-w

Nelson, R. R. (2003). Physical and Social Technologies and Their Evolution, Working Paper. Laboratory of Economics and Management, Sant'Anna School of Advanced Studies, Pisa, Italy.

Nenonen, S., Gummerus, J., \& Sklyar, A. (2018). Game-changers: Dynamic capabilities' influence on service ecosystems. Journal of Service Management, 29, 4.

Nguyen, D. H., de Leeuw, S., \& Dullaert, W. E. (2018). Consumer behaviour and order fulfilment in online retailing: A systematic review. International Journal of Management Reviews, 20(2), 255-276. 
Ofli, F., Meier, P., Imran, M., Castillo, C., Tuia, D., Rey, N., Briant, J., Millet, P., Reinhard, F., Parkan, M., \& Joost, S. (2016). Combining human computing and machine learning to make sense of big (aerial) data for disaster response. Big Data, 4(1), 47-59.

Ordanini, A., \& Parasuraman, A. (2011). Service innovation viewed through a service-dominant logic lens: A conceptual framework and empirical analysis. Journal of Service Research, 14(1), 3-23.

Ostrom, A. L., Parasuraman, A., Bowen, D. E., Patrício, L., \& Voss, C. A. (2015). Service research priorities in a rapidly changing context. Journal of Service Research, 18, 127-159.

Overby, S. (2013). Invasion of the data scientists. (cover story). CIO, 26, 30-38.

Özdamar, L., \& Ertem, M. A. (2015). Models, solutions and enabling technologies in humanitarian logistics. European Journal of Operational Research, 244(1), 55-65.

Papadopoulos, T., Gunasekaran, A., Dubey, R., Altay, N., Childe, S. J., \& Fosso-Wamba, S. (2017). The role of Big Data in explaining disaster resilience in supply chains for sustainability. Journal of Cleaner Production, 142, 1108-1118.

Parker, H., \& Ameen, K. (2018). The role of resilience capabilities in shaping how firms respond to disruptions. Journal of Business Research, 88, 535-541.

Pires, G. D., Stanton, J., \& Rita, P. (2006). The internet, consumer empowerment and marketing strategies. European Journal of Marketing, 40, 936-949.

Popovič, A., Hackney, R., Tassabehji, R., \& Castelli, M. (2018). The impact of big data analytics on firms' high value business performance. Information Systems Frontiers, 20(2), 209-222.

Prasad, S., Zakaria, R., \& Altay, N. (2018). Big data in humanitarian supply chain networks: A resource dependence perspective. Annals of Operations Research, 270(1), 383-413.

Prasanna, S. R. (2021). The role of supplier innovativeness in the humanitarian context. Annals of Operations Research. https://doi.org/10.1007/s10479-021-04065-5

Privett, N. (2016). Information visibility in humanitarian operations: Current state-of-the-art. In C. Zobel, N. Altay, \& M. Haselkorn (Eds.), Advances in managing humanitarian operations (pp. 159-183). Springer.

Psoinos, A., Kern, T., \& Smithson, S. (2000). An exploratory study of information systems in support of employee empowerment. Journal of Information Technology, 15, 211-230.

Queiroz, M., Tallon, P. P., Sharma, R., \& Coltman, T. (2018). The role of IT application orchestration capability in improving agility and performance. The Journal of Strategic Information Systems, 27(1), 4-21.

Rafiq, M., \& Ahmed, P. K. (1998). A customer-oriented framework for empowering service employees. Journal of Services Marketing, 12, 379-396.

Randhawa, K., Wilden, R., \& Gudergan, S. (2018). Open service innovation: The role of intermediary capabilities. Journal of Product Innovation Management, 35(5), 808-838.

Randolph, W. A. (1995). Navigating the journey to empowerment. Organizational Dynamics, 23, 19-32.

Ransbotham, S., Kiron, D., \& Prentice, P. K., (2015). The Talent Dividend: Analytics talent is driving competitive advantage at data-oriented companies. MIT Sloan Management Review. MIT, Cambridge, MA.

Rogg, K. L., Schmidt, D. B., Shull, C., \& Schmitt, N. (2001). Human resource practices, organizational climate, and customer satisfaction. Journal of Management, 27, 431-449.

Sarstedt, M., Hair, J. F., Cheah, J.-H., Becker, J.-M., \& Ringle, C. M. (2019). How to specify, estimate, and validate higher-order constructs in PLS-SEM. Australasian Marketing Journal, 27(3), 197-211.

Schilke, O. (2014). Second-order dynamic capabilities: How do they matter? Academy of Management Perspectives, 28(4), 368-380.

Schilke, O., \& Goerzen, A. (2010). Alliance management capability: An investigation of the construct and its measurement. Journal of Management, 36(5), 1192-1219.

Schilke, O., Hu, S., \& Helfat, C. E. (2018). Quo vadis, dynamic capabilities? A content-analytic review of the current state of knowledge and recommendations for future research. Academy of Management Annals, 12(1), 390-439.

Schneider, B., \& Bowen, D. E. (2019). Perspectives on the Organizational Context of Frontlines: A Commentary. Journal of Service Research, 22, 3-7.

Schniederjans, D. G., Ozpolat, K., \& Chen, Y. (2016). Humanitarian supply chain use of cloud computing. Supply Chain Management: An International Journal, 21(5), 569-588.

Schoemaker, P. J., Heaton, S., \& Teece, D. (2018). Innovation, dynamic capabilities, and leadership. California Management Review, 61(1), 15-42.

Shan, S., Wang, L., Li, L., \& Chen, Y. (2012). An emergency response decision support system framework for application in e-government. Information Technology and Management, 13(4), 411-427.

Sharma, P., \& Joshi, A. (2019). Challenges of using big data for humanitarian relief: Lessons from the literature. Journal of Humanitarian Logistics and Supply Chain Management, 10(4), 423-446.

Sheng, J., Amankwah-Amoah, J., Khan, Z., \& Wang, X. (2020). COVID-19 Pandemic in the new era of big data analytics: Methodological innovations and future research directions. British Journal of Management. https://doi.org/10.1111/1467-8551.12441 
Singh, J., \& Saatcioglu, A. (2008). Role theory approaches for effectiveness for effectiveness of markettingoriented boundary spanners. Review of Marketing Research, 147-181.

Spreitzer, G. M. (1995). Psychological empowerment in the workplace: Dimensions, measurement, and validation. Academy of Management Journal, 38, 1442-1465.

Sky News. (2021). COVID-19: India coronavirus cases soar past 20 million with health system on brink of collapse, COVID-19: India coronavirus cases soar past 20 million with health system on brink of collapse I World News I Sky News

Tatikonda, L. U., \& Tatikonda, R. J. (1996). Top ten reasons your TQM effort is failing to improve profit. Production and Inventory Management Journal, 37, 5-9.

Teece, D. J. (2007). Explicating dynamic capabilities: The nature and microfoundations of (sustainable) enterprise performance. Strategic Management Journal, 28, 1319-1350.

Teece, D. J. (2009). Dynamic capabilities and strategic management: Organizing for innovation and growth. Oxford University Press on Demand.

Teece, D. J., Pisano, G., \& Shuen, A. (1997). Dynamic capabilities and strategic management. Strategic Management Journal, 18(7), 509-533.

Thamizhmanii, S., \& Hasan, S. (2010). A review on an employee empowerment in TQM practice. Journal of Achievements in Materials and Manufacturing Engineering, 39, 204-210.

The Economist. (2017). The world's most valuable resource is no longer oil, but data. Accessed on May 6, 2021. https://www.economist.com/leaders/2017/05/06/the-worlds-most-valuable-resource-isno-longer-oil-but-data

Tran, Y., Zahra, S., \& Hughes, M. (2019). A process model of the maturation of a new dynamic capability. Industrial Marketing Management, 83, 115-127.

Tranfield, D., Denyer, D., \& Smart, P. (2003). Towards a methodology for developing evidence-informed management knowledge by means of systematic review. British Journal of Management, 14(3), 207-222.

Tuckett, A. G. (2005). Applying thematic analysis theory to practice: A researcher's experience. Contemporary Nurse, 19, 75-87.

Vargo, S. L., Maglio, P. P., \& Akaka, M. A. (2008). On value and value co-creation: A service systems and service logic perspective. European Management Journal, 26(3), 145-152.

Vesset, D., \& Olofson, C. W. (2014). Big data in the enterprise: when worlds collide, white paper by IDC. International Data Corporation (IDC), Framingham, MA, 1:17.

Voegtlin, C., Boehm, S. A., \& Bruch, H. (2015). How to empower employees: Using training to enhance work units' collective empowerment. International Journal of Manpower, 36, 354-373.

Wamba, S. F., \& Akter, S. (2019). Understanding supply chain analytics capabilities and agility for datarich environments. International Journal of Operations and Production Management. https://doi.org/10. 1108/IJOPM-01-2019-0025

Wamba, S. F., Akter, S., Edwards, A., Chopin, G., \& Gnanzou, D. (2015). How 'big data' can make big impact: Findings from a systematic review and a longitudinal case study. International Journal of Production Economics, 165, 234-246.

Wamba, S. F., Edwards, A., \& Akter, S. (2019). Social media adoption and use for improved emergency services operations: The case of the NSW SES. Annals of Operations Research, 283(1), 225-245.

Wamba, S. F., Gunasekaran, A., Akter, S., Ren, S. J. F., Dubey, R., \& Childe, S. J. (2017). Big data analytics and firm performance: Effects of dynamic capabilities. Journal of Business Research, 70, 356-365.

Wamba, S. F., Gunasekaran, A., Dubey, R., \& Ngai, E. W. T. (2018). Big data analytics in operations and supply chain management. Annals of Operations Research, 270(1), 1-4.

Wilden, R., Akaka, M. A., Karpen, I. O., \& Hohberger, J. (2017). The evolution and prospects of servicedominant logic: An investigation of past, present, and future research. Journal of Service Research, 20(4), 345-361.

Wilder, K. M., Collier, J. E., \& Barnes, D. C. (2014). Tailoring to customers' needs: Understanding how to promote an adaptive service experience with frontline employees. Journal of Service Research, 17(4), $446-459$.

Winter, S. G. (2003). Understanding dynamic capabilities. Strategic Management Journal, 24(10), 991-995.

Wirtz, J., \& Jerger, C. (2016). Managing service employees: Literature review, expert opinions, and research directions. Service Industries Journal, 36, 757-788.

World Economic Forum. (2020). How AI and machine learning are helping to fight COVID-19. Retrieved November 19. https://www.weforum.org/agenda/2020/05/how-ai-and-machine-learning-are-helping-tofight-covid-19/

Zahra, S. A., Sapienza, H. J., \& Davidsson, P. (2006). Entrepreneurship and dynamic capabilities: A review model and research agenda. Journal of Management Studies, 43(4), 917-955. 
Publisher's Note Springer Nature remains neutral with regard to jurisdictional claims in published maps and institutional affiliations. 